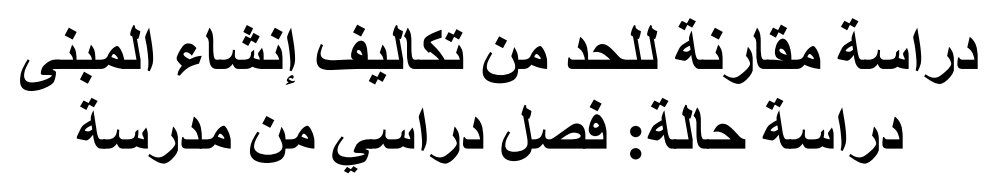

\title{
A Comparative Study to Reduce the Construction Costs of the Building, Case Study: Class Room of a School
}

\author{
Prof. Mohamed Esmat Hamed El- \\ Attar \\ Professor of Architecture, Department \\ of Architecture, Mansoura University
}

\author{
Eng. Adel Abd-Alhakiem Abd- \\ Allah \\ General Director of Inspection, \\ Authority for Educational Buildings
}

\begin{abstract}
Looking at the building from the economic point of view we must study the factors that control the prices of materials used in its production. The research discusses the possibility of reducing the costs of constructing the building on three approaches; design: both architectural or structural design in addition to design complementary and maintenance work; raw materials which are the major factor in the cost, even if they cannot reduce the price, but can be reduced by use, labor which is the factor that can be minimized by the development of the construction industry. The research aims through a set of preferences to reduce the construction cost of a class room unit of a school building. The research concluded that it could reduce the cost of constructing a class room unit significantly by architectural elements and the choice of architectural proportions of the class room so that reduces the perimeter, and it reduces the cost of the raw materials and labor used during construction.
\end{abstract}

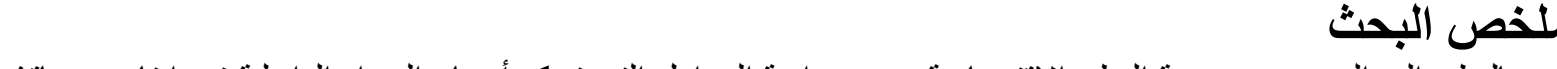

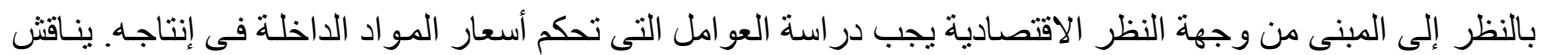

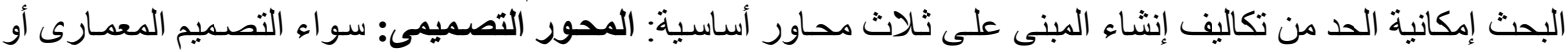

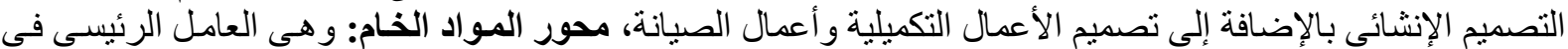

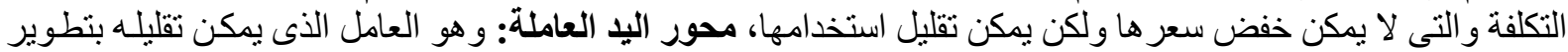

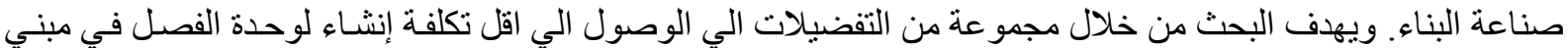

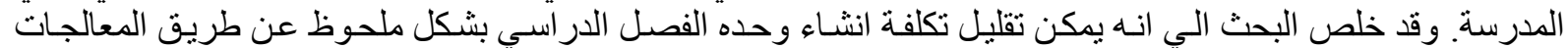
المعمارية واختيار نسب الفصل الدر اسي بحيث تقلل المحيط، وذللك يقلل من تكاليف ألخامات المستخدمة ولئ والعمالة. الكلمات الدالة: مدرسة ــ فصل در أسي ـ ــكاليف إنشاء.

نشأت صناعة البناء و المو اد الخام التى حولت

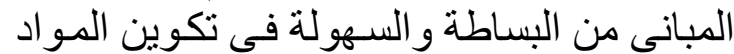

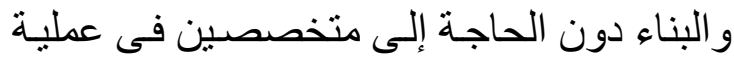

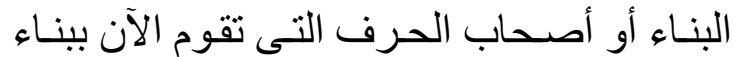

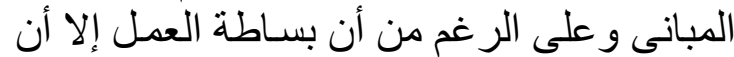

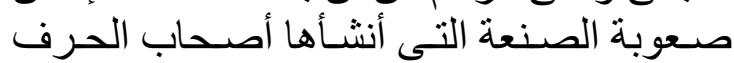

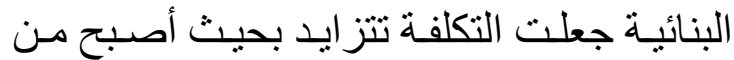

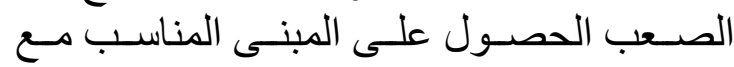
ارتفاع تكاليفه.

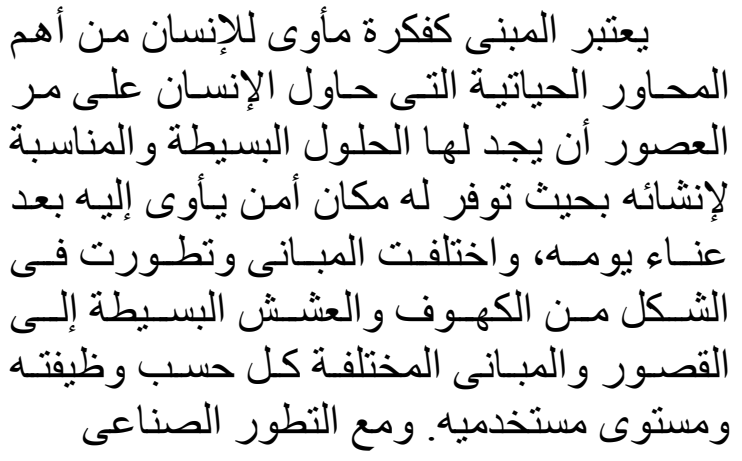


A: 28 Mohamed Esmat Hamed El-Attar and Adel Abd-Alhakiem Abd-Allah

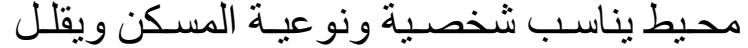
التكلفة الناتجة عن استخدام المواد الخام.

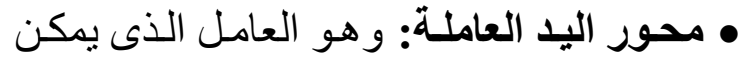

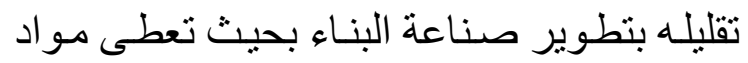

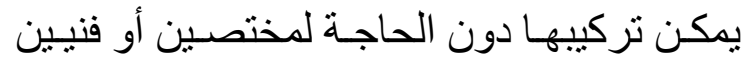
على درجة كفاءة عالية.

\section{1- المحور التصميمى:}

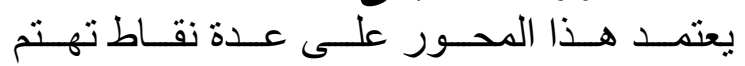

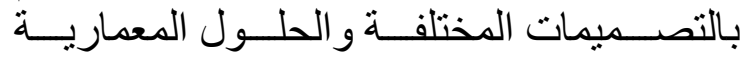

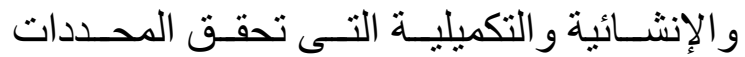
التصميمية بصورة تقلل من الأوزان و التكلفة.

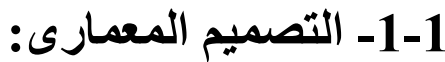

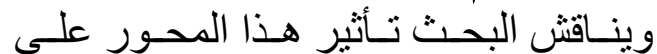

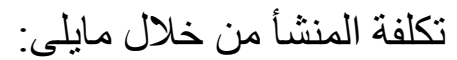

\section{1-1-1 استخدام مساحات أكبر ومحيط}

$$
\text { أقلّ: }
$$

تختلف العلاقة بين المسـاحة و المحبط تبعاً لثكل المساحة التى تمثل محور المنفعة بالنسبة

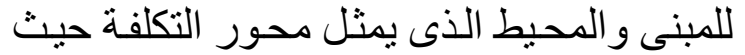

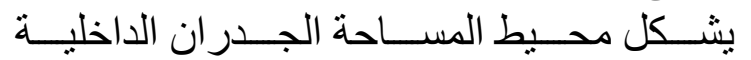

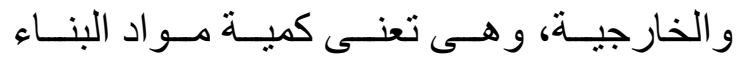

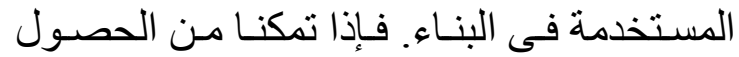

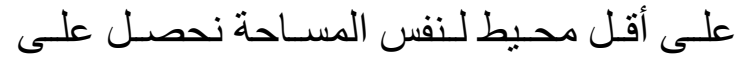

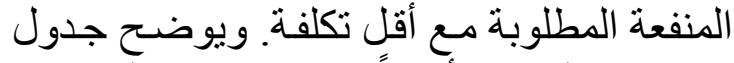

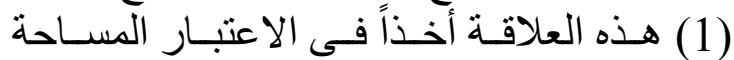

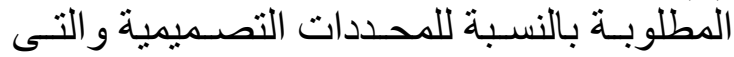

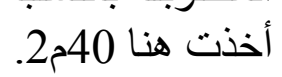

وينظــر إلــى المبنــى مـن وجهـــة النظــر

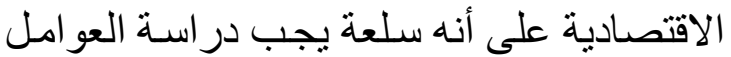

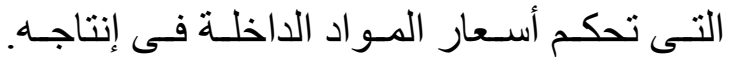

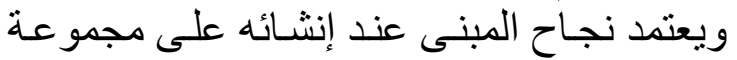

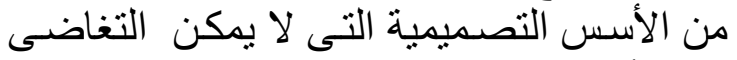

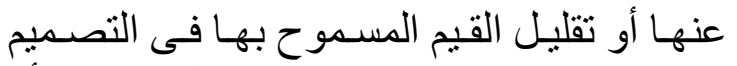

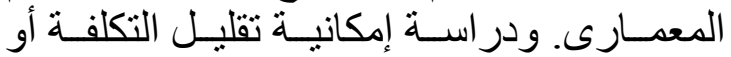

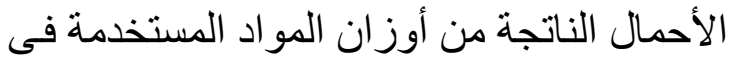

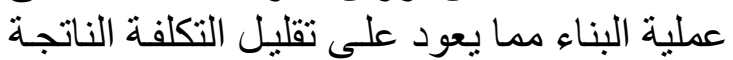

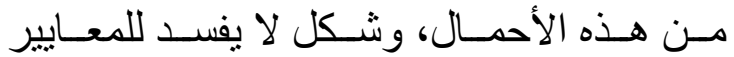

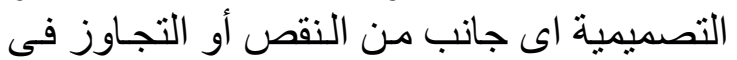

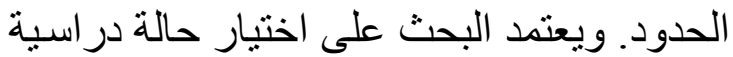

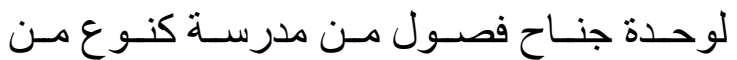

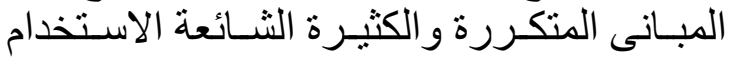

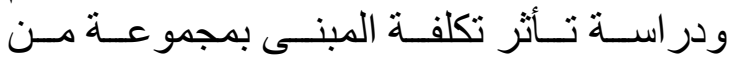

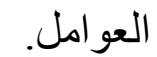
ويعتمد البحث في در اسـة إمكانيـة الحد مـن إنـ

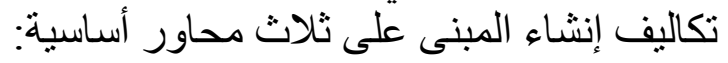

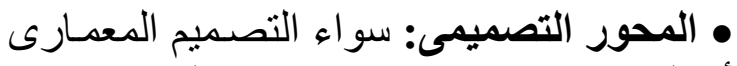

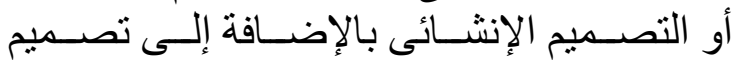

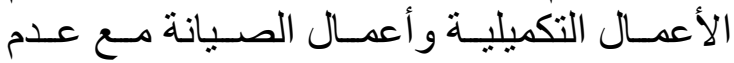

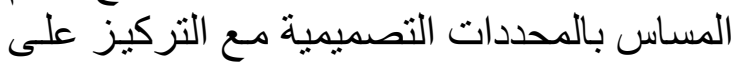

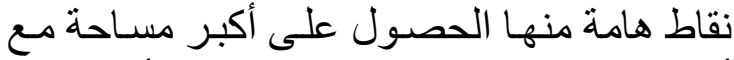
أقل محيط واستخدام عناصر معماريـة أقل تكلفة الفية

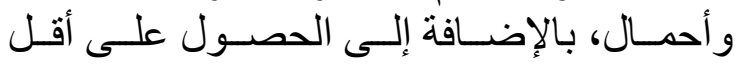
قطاعات خرسانية في العناصر الإنشائية.

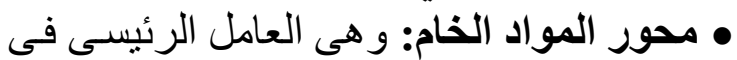

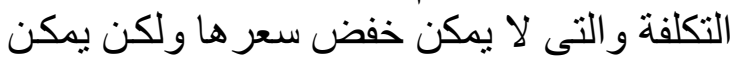

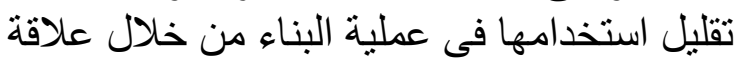

\begin{tabular}{|c|c|c|c|}
\hline المحيط & طول الضلع & طول الضلع & الشكل الهندسى \\
\hline 2 ? 25.32 & 6.33 & م 6.33 & المربع 40م22 \\
\hline $\begin{array}{l}26.00 \\
28.00 \\
2 \\
2 \\
2 \\
2 \\
2 \\
2 \\
2 \\
2 \\
24.6600\end{array}$ & $\begin{array}{l}8.00 \\
10.00 \\
\text { م } 13.33 \\
20.00\end{array}$ & $\begin{array}{l}5.00 \\
4.00 \\
\text { P } 3.00 \\
2.00\end{array}$ & المستطيل 40م² \\
\hline 22.50 & - & القطر= 7.166 م & الأئرة 40م22 \\
\hline
\end{tabular}

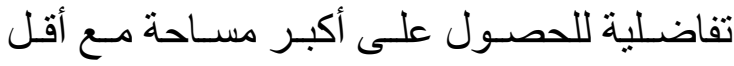

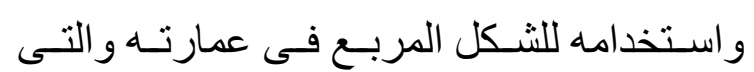

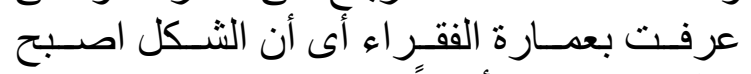
وظيفة اقتصادية أيضاً).
ومن الجدول السابق نلاحظ أن المحيط يقل

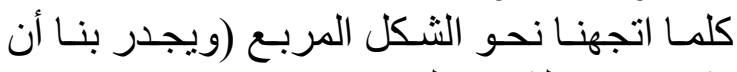

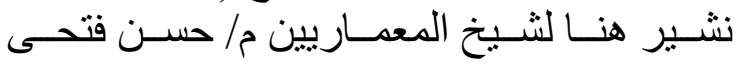




\begin{tabular}{|c|c|c|c|c|c|c|c|c|c|}
\hline \multirow{2}{*}{$\begin{array}{l}\overline{3} \\
\overline{3} \\
\overline{3}\end{array}$} & \multicolumn{6}{|c|}{ ו דمس } & \multirow{2}{*}{ 牙 } & \multirow[b]{2}{*}{ y } & \multirow{2}{*}{ والمحددات } \\
\hline & $\begin{array}{l}\overline{3} \\
\text { aे }\end{array}$ & 可寻 & 䒚牙. & 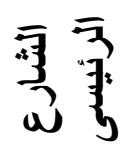 & $\overline{\bar{j}} \overline{\overline{3}}$ & $\begin{array}{l}\overline{7} \overline{3} \\
\text { 寻: }\end{array}$ & & & \\
\hline 240 & 20 & - & 10 & - & 10 & - & 40 & 12 & الفصل \\
\hline 24.0 & 24 & - & 3 & 8 & 5 & 8 & 12 & 1 & حجرة المدير \\
\hline 51 & 17 & 6 & 8 & - & 3 & - & 60 & 3 & المعمل \\
\hline 28 & 14 & - & 10 & 2 & - & 2 & 45 & 2 & سلالم الطلبة \\
\hline 9 & 9 & - & 8 & - & - & 1 & 1000 & 1 & الملاعب \\
\hline 274 & 23 & 10 & 7 & 6 & - & - & 4 & 12 & دورة المياه \\
\hline 626 & 107 & 16 & 46 & 16 & 18 & 11 & & موع & \\
\hline
\end{tabular}

جدول (2): الوزن النوعى للعلاقة بين عناصر التصميم المختلفة لمبنى الفصول.

العزل الموجودة في الدور الأرضـى لتحل مكان

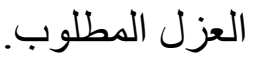

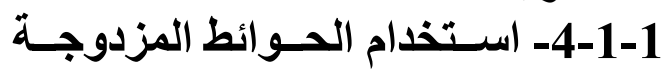
بالحوائط الخارجية:

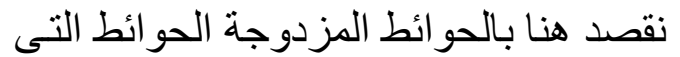

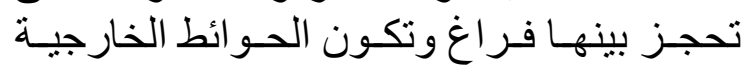

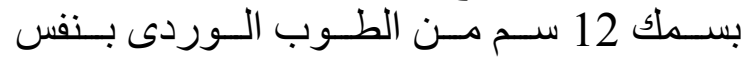

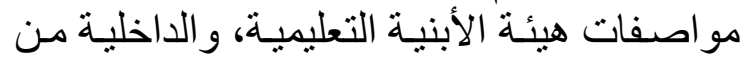

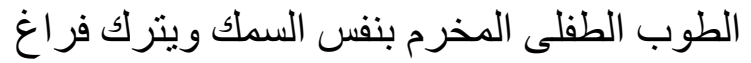

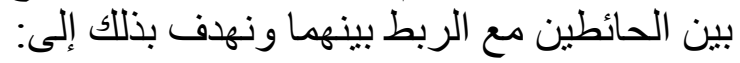

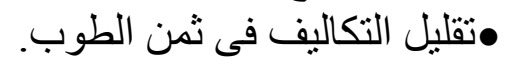

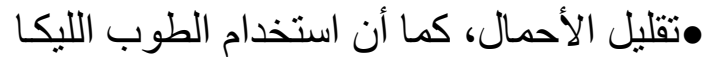

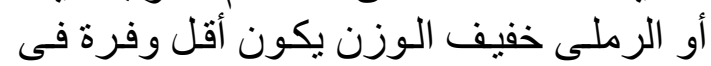

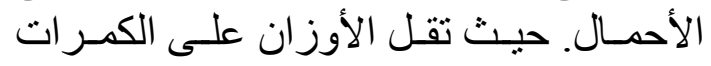
فيقل ارتفاعها. •زيادة قوة تماسك البياض مع السطح الداخلى لمالى المبنى بالطوب الطفلى.

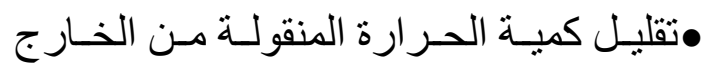

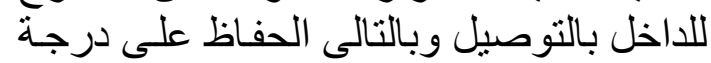
الحرارة الداخلية بالفصل. بلفيل •تسهيل حل مشكلة تثبيت الشبابيك الألومنيوم

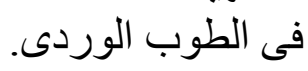
المناخد الطاردة:-1-1-1 تقليل ارتفاع الأدوار فى الأقاليم المناخية الباردة: يفيد زيادة ارتفاع الدور فى تقليل الإحساس التهاس

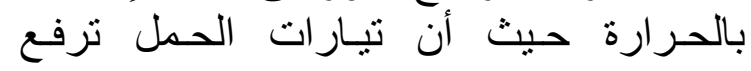

بدر اسة تحليلية للجدول السـابق- وهو جزء التهاء

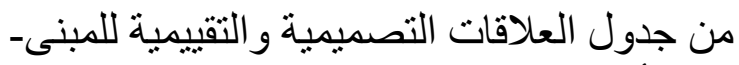

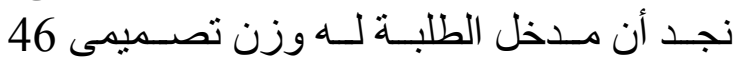

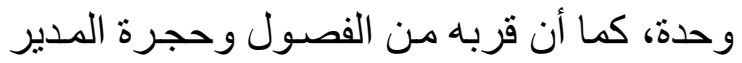

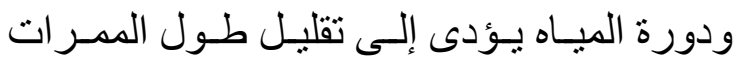

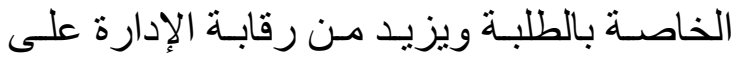
حركة دخول وخروج الطلبة.

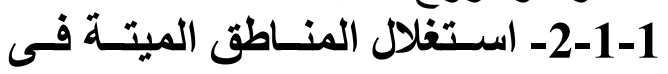

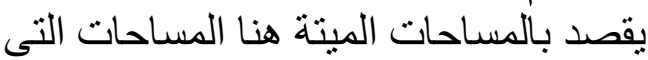

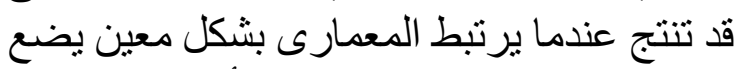

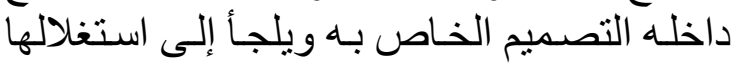

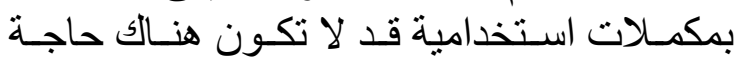

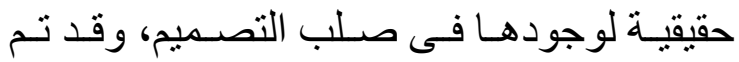
تصـميم جدول (2) للعلافـات يمكن بـاسـتخدامه وهيه الحصـول على أقل مسـاحات ميتة تتو اجد داخل بـل بـل

تعثبر المعالمع المعامل بالدور الأرضى:

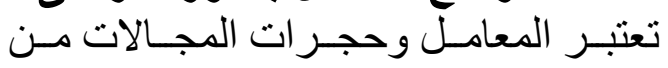

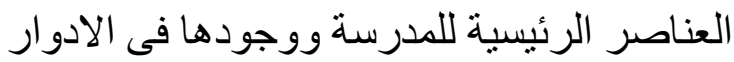

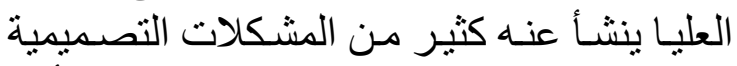

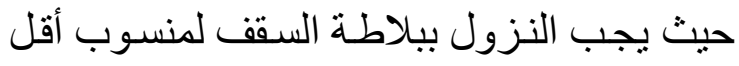
من منسوب سطح بلاطـة سقف الدور مدـا ينتج

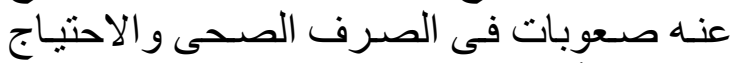

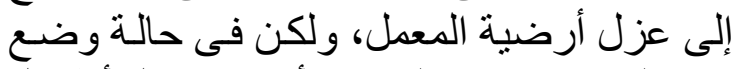

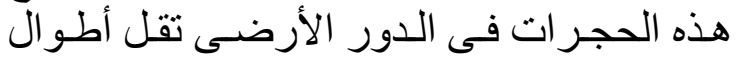
مسار ات التغذية و الصرف الت وكذللك استغلال طبقل 
A: 30 Mohamed Esmat Hamed El-Attar and Adel Abd-Alhakiem Abd-Allah

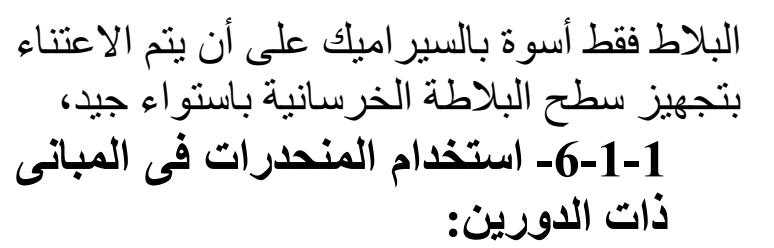

الهواء الساخن إلى أعلى. أما فى المناطق الباردة والساحلية فيمكن تقليل هذاء الإلى الارتفاع بمقدار من10 إلى 15 سم. وفى جميع المناطق

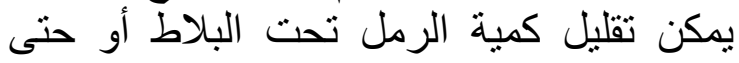

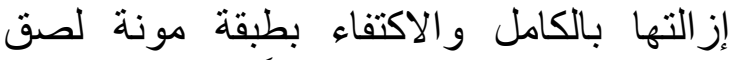

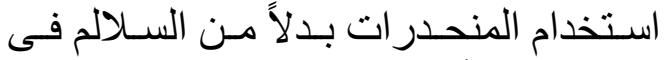
الوصول للاور الأول يجعل من الممكن استخدام

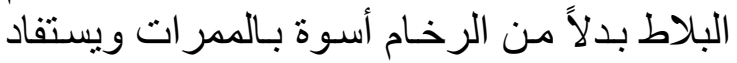
من ذلك فى تقليل الأوزان و التكلفة.
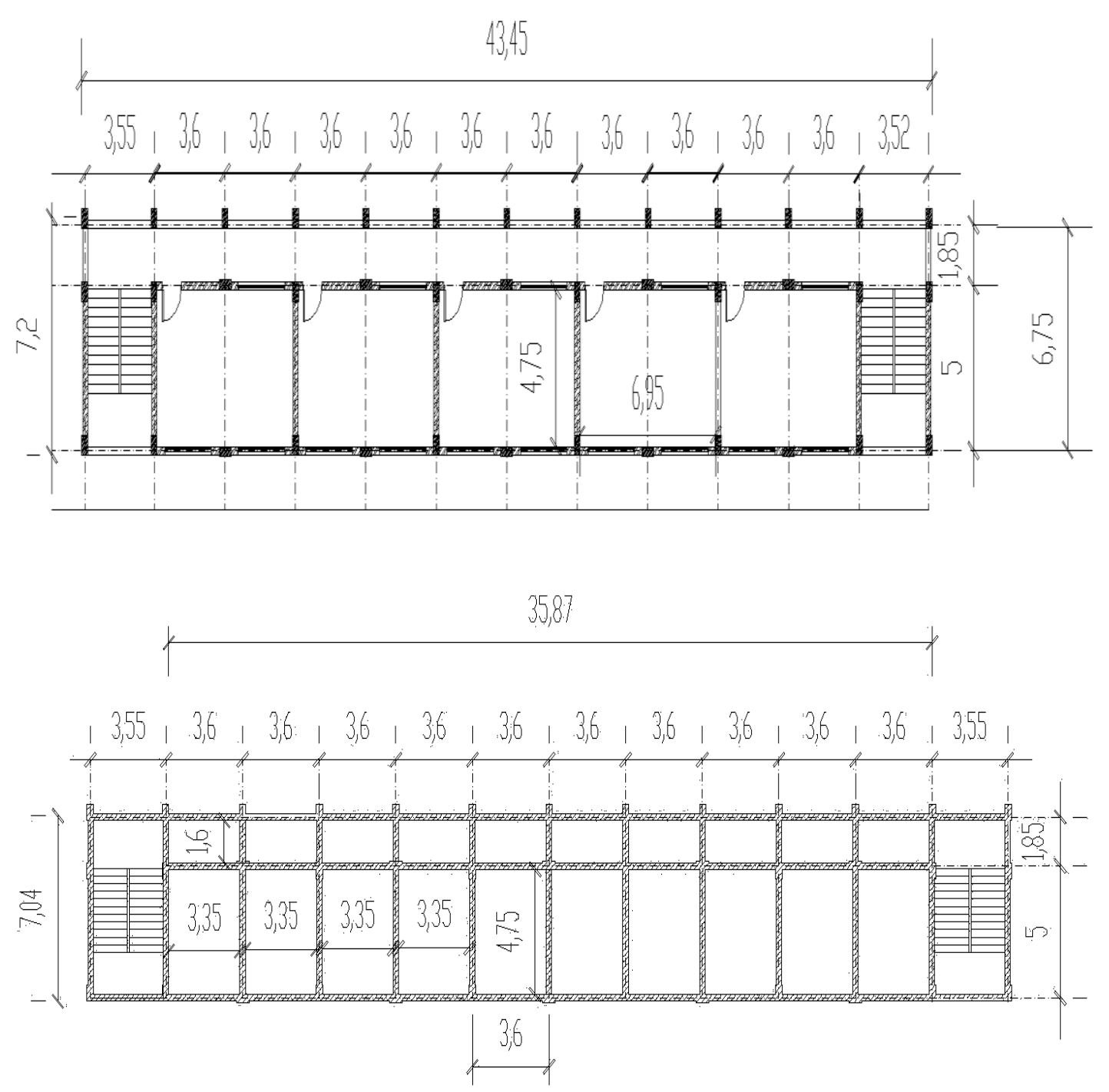

ويوضح شكل (1) وشكل (2) نموذجان لجناح

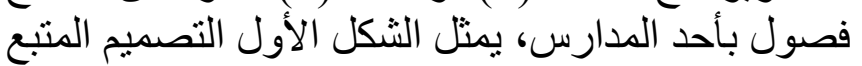

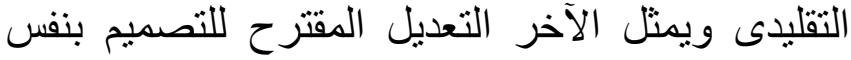

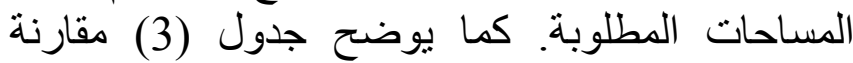

لحصر تقريبى لبعض البنود المستخدمة. 
شكل (1): نموذج( أ ) يمثل لجناح فصول بمدرسة عبارة عن خمسة فصول لعدد خمسة أدو ار.
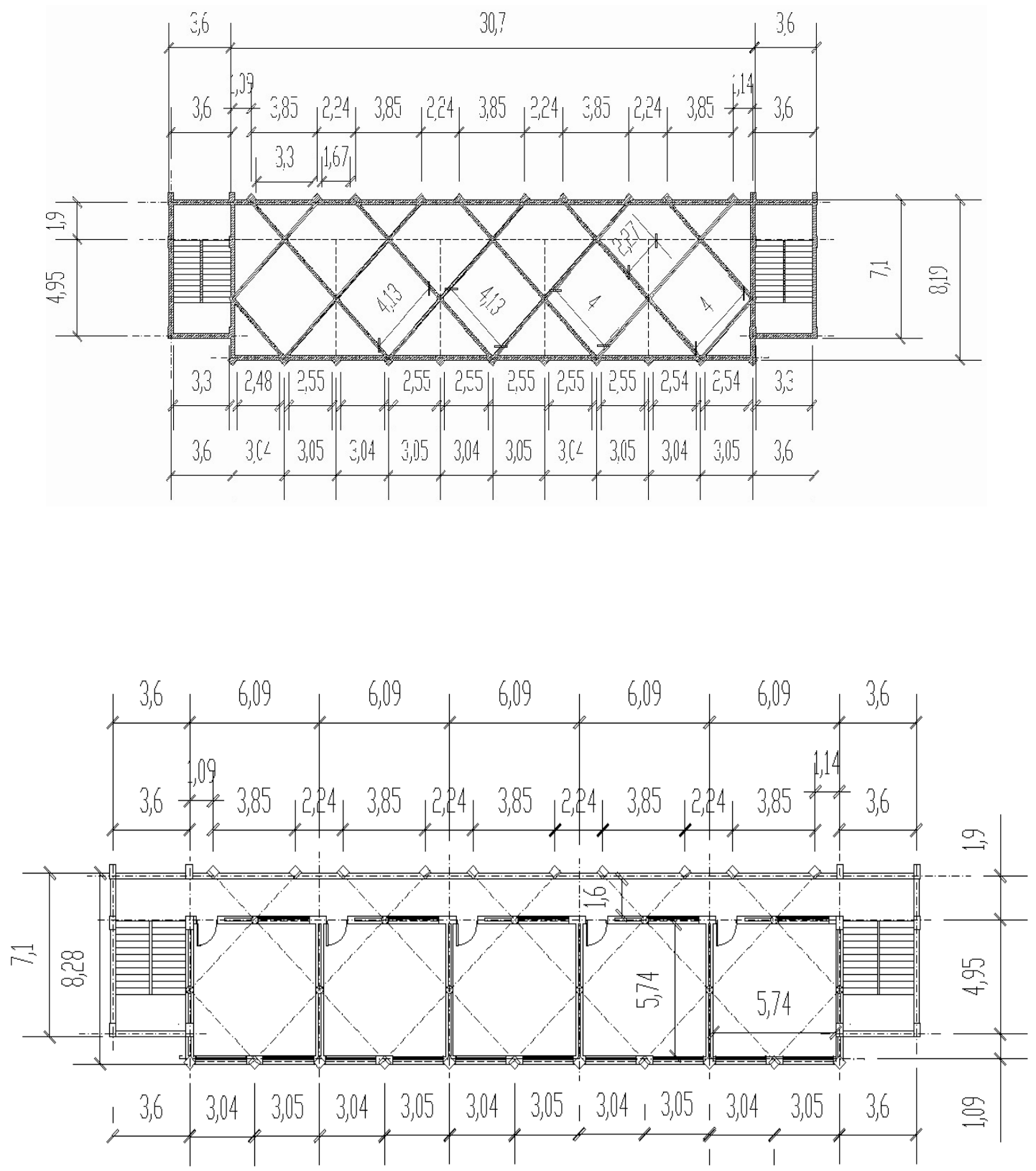

شكل (2): نموذج ( ب ) مقترح يمثل نفس المحددات بالنموذج ( أ ) ولكن يوفر فى التكلفة.

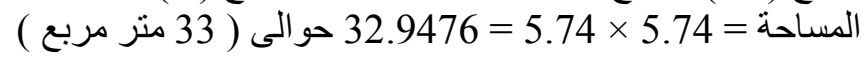


A: 32 Mohamed Esmat Hamed El-Attar and Adel Abd-Alhakiem Abd-Allah

\begin{tabular}{|c|c|c|c|c|}
\hline \multicolumn{2}{|c|}{ الفرق } & \multirow{2}{*}{ القيمة } & \multirow{2}{*}{ النموذج } & \multirow{2}{*}{ البند } \\
\hline بالموجب & بالسالب & & & \\
\hline \multirow[b]{2}{*}{ - } & \multirow{2}{*}{90.7086} & 349.575 & i & \multirow{2}{*}{ لخرسانة } \\
\hline & & 258.8664 & ب & \\
\hline \multirow[b]{2}{*}{-} & \multirow{2}{*}{22.5025} & 894.8325 & أ & \multirow{2}{*}{ البلاط } \\
\hline & & 872.33 & ب ب & \\
\hline \multirow{2}{*}{120.0575} & & 271.3125 & i & \multirow{2}{*}{ المبانى } \\
\hline & - & 391.37 & ب & \\
\hline \multirow[b]{2}{*}{ - } & \multirow{2}{*}{48.3725} & 3311.563 & أ & \multirow{2}{*}{ الدهانات } \\
\hline & & 3263.19 & ب ب & \\
\hline
\end{tabular}

عدد الكمر ات وقلة القطاعات.

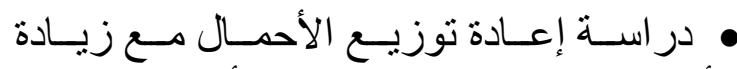

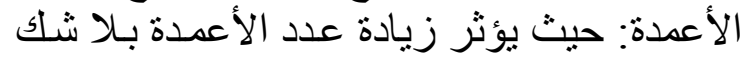

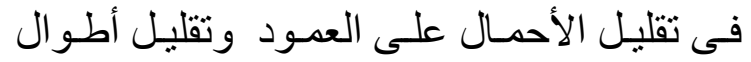

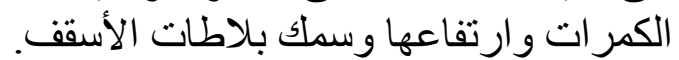

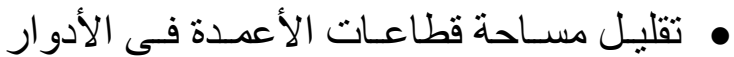
العليا.

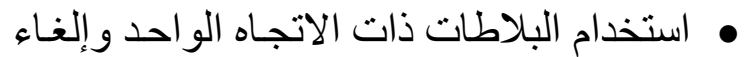
الكمر ات العرضية.

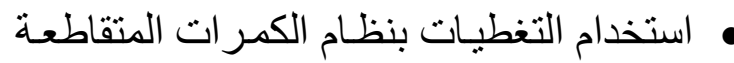
فى المساحات الكبيرة. (Waffle)

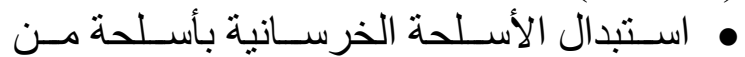
الألومنيوم المدهون بالبولى استر.
من در اسة النتائج بالجدول نجد:

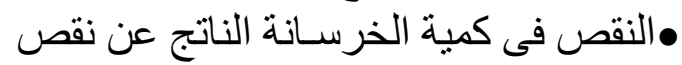
•قصص البلاط نـاتج عن نقص طول فرل الممرات

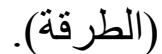
•زيـادة كميـة المبـانى نـاتج مـن زيـادة ارتفـاع

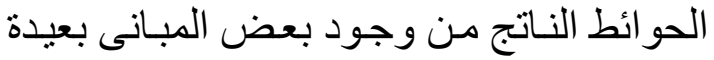
عن الكمر ات. التط التهر

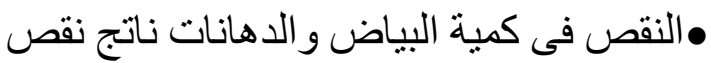
أطو ال الحو ائط (نقص المحيط للفصل). • النقص فى الكميات يعنى النقص فى الأحمال

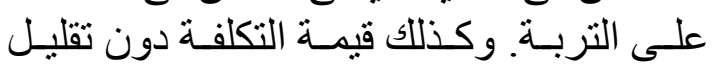
للمحددات التصميمية المطلوبة. 2-1 التصميم الإنشائى:

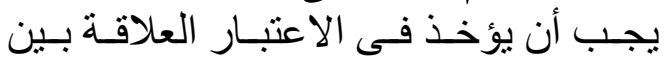

التكلفة الفعلية لتقليل الأحمال و التى يمكن أن تزيد التهار

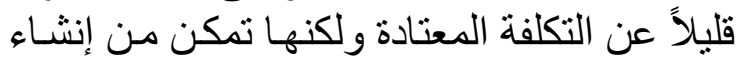

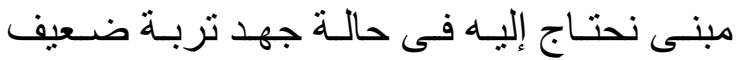
ويكون العائد النفحى أكبر بكثير ــ ونرى فيى هذه

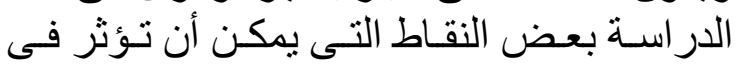
تقليل تكلفة الإنشاء منها: 
عمره الافتر اضى ومدى معالجة المبنى للظروف

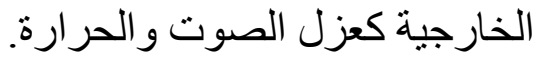

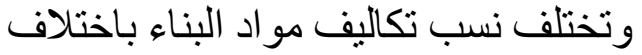

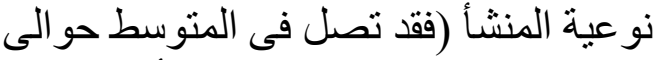

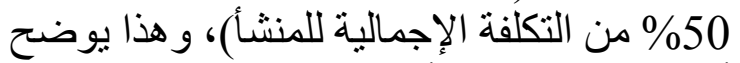
أهمية مو اد البناء وتأثثير ها المباثُر على تكلفة

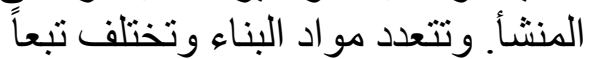
لاستخداماتها فهناك مو اد إنشائية و أخرى غير النياء

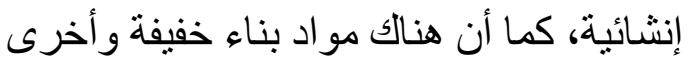

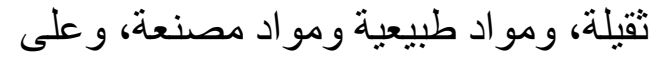

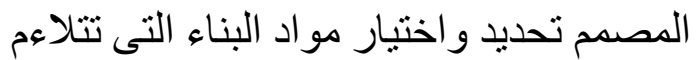

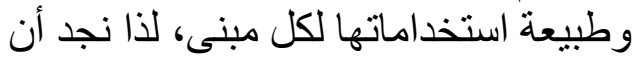

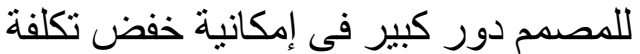

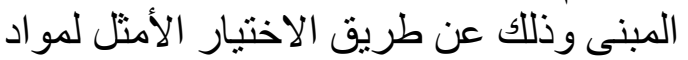

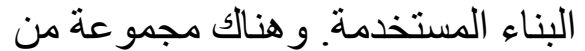
الاعتبار ات يجب مر اعاتها عند اختيار المواد اد هون

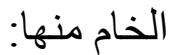
ـ أن تكون مناسبة للاستعمالات المختلفة وتحقق الأغر اض التى تستعمل من أجلها.

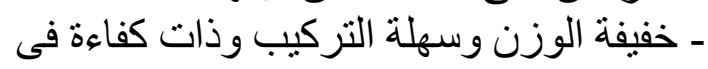
العزل الحرارى و الصونه الصنى. ـ إمكانية تقليل احتمالات التلف و واله الهالك،

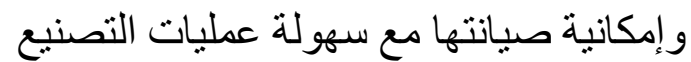
خاصة لتلك التى تتم فى المو اقع. و على ذللك فإنه بمكن تقليل تكلفة إنشاء المبنى بصفة عامة ومبنى جناح الفصول بصفة بلاء خاصة باتباع الآتى: لمامة • استخدام الحو ائط من الطوب الخفيف. • استخدام حو ائط سابقة التصنيع خفيفة الوزن. • استخدام الهياكل المعدنية.

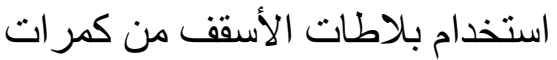
خرسانية وبلوكات الأجر.

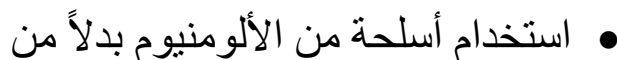

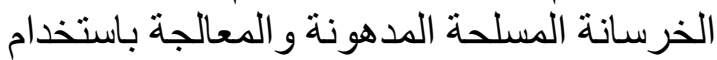
(البولى استر). • إضافة أكاسيد الألوان لمادة البياض و عدم البـان

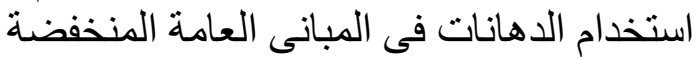

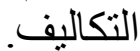
• استخدام مادة البرليت كطبقة ميول و عزل

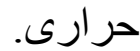
عمل تصميم جديد لطبقات ميول الأسقف ومذاريب الصرف بها.

\section{3-1 - تصميم الأعمال التكميلية:}

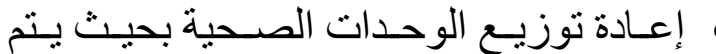

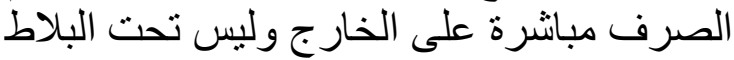

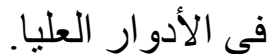

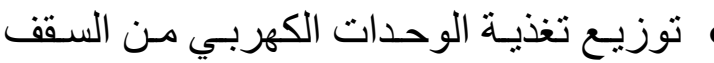
وليس من الحو ائط.

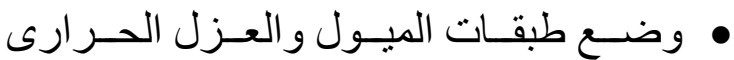
و الرطوبة بالأسطح.

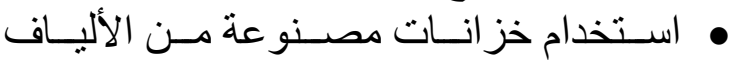
الزجاجية المدعم بالإيبوكسى فى غرف التفتيش

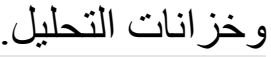

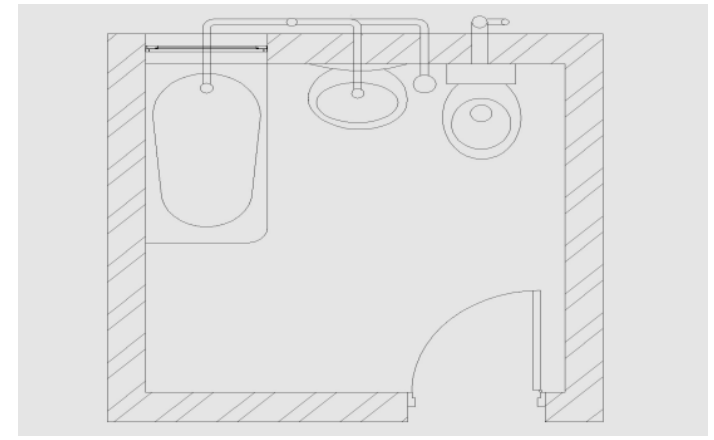

\section{4-1 تصميم أعمال الصيانة:}

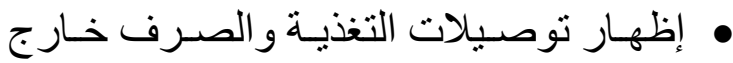
الحو ائط. • عدم خفض بلاطة الحمامات و المطابخ.

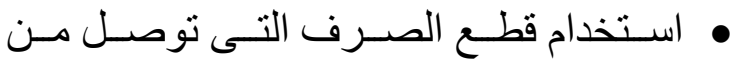
الجهاز إلى عامود الصرف مبن مباثرة.

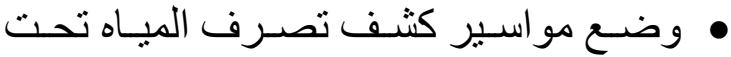
البلاط فى الحمامات و المطابخ. وضـع مو اسيـر تتفيس الرطوبـة فـى الأمساكن ت

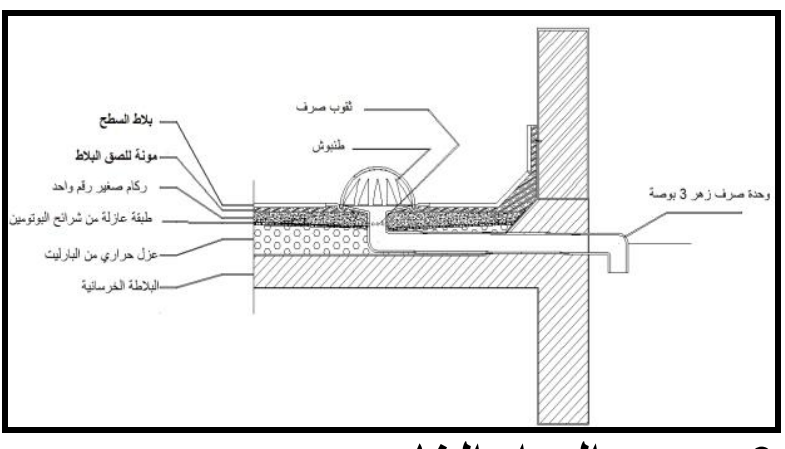

2- محور المواد الخام:

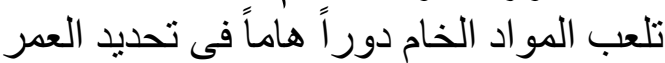

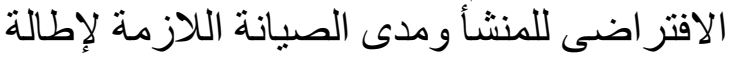


A: 34 Mohamed Esmat Hamed El-Attar and Adel Abd-Alhakiem Abd-Allah

• • مهارة وكفاءة الإدارة والإشر اف ممـا يؤدى الفي

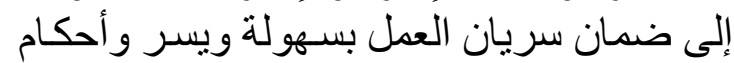

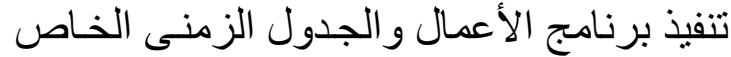

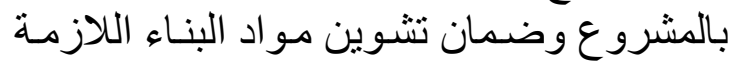
قبل الاحتياج إلبها. نتيجة البحث:

ومما سبق يرى البحث أنه يمكن تقليل تكلفة

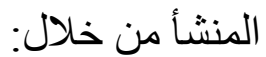

• استخدام الوحدات السابقة التجهيز الخفيفة.

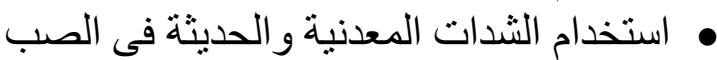

مثل (TUNELL SYSTEM).

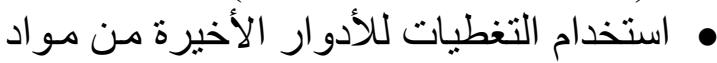

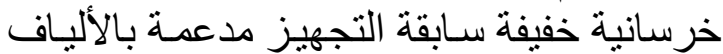
الزجاجية أو البوليستر.

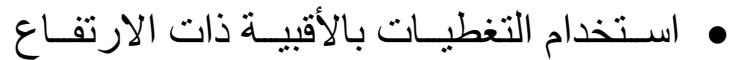

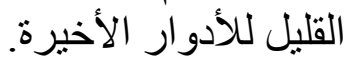

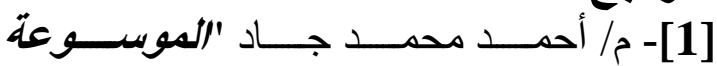

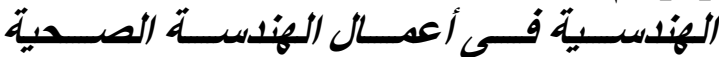

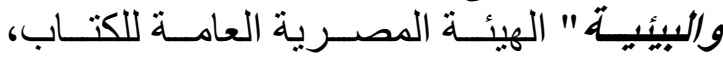

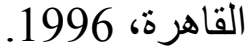

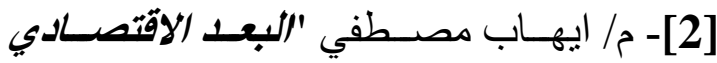

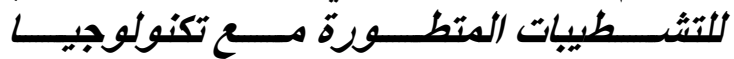

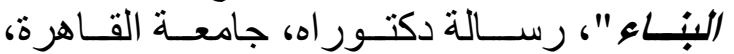
2001

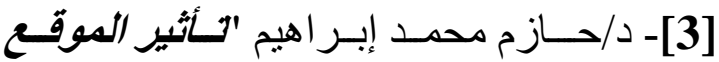

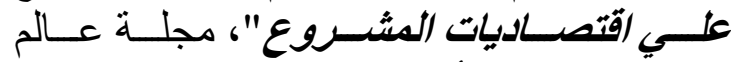
البناء، العدد 21، أبريل 1982.

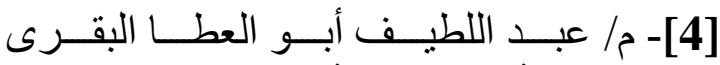

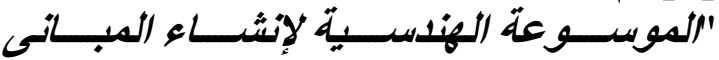

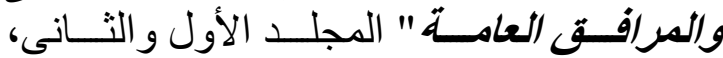

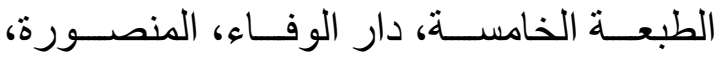
.1994

[5] - م/ محمــد صــلاح "الــتحكم فــي تكلفــة

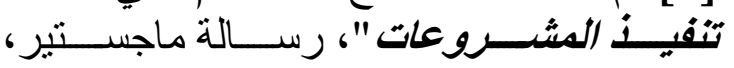
جامعة القاهرة، 1996.

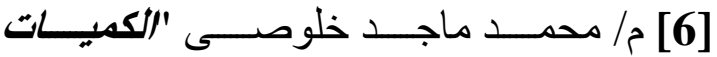

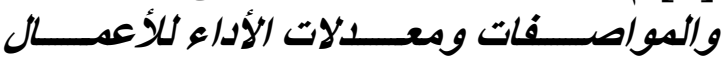

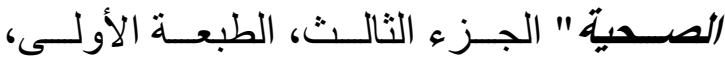
مطبعة النهضة العربية، القاهرة، 1994.
3- 3حور العمالة:

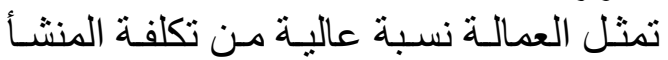
(تنراوح بين 20- 45\%) حسب مستوى الميكنة

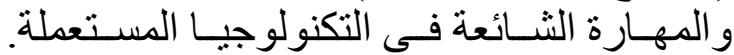

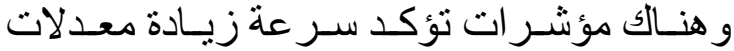

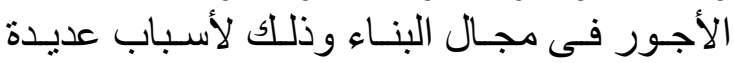
أهمها:

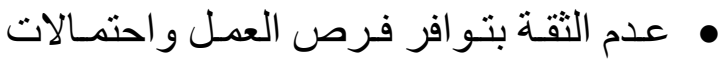

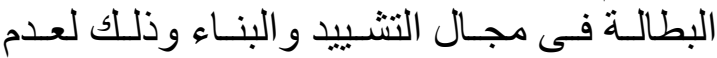

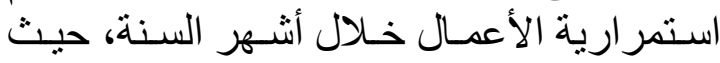

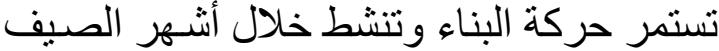

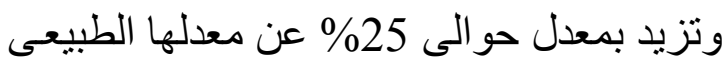

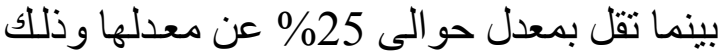

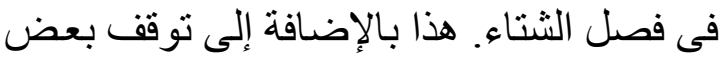

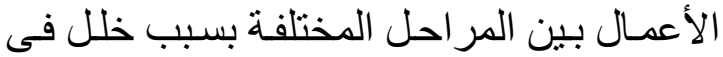
جدولة وتجهيز الأعمال المختلفة.

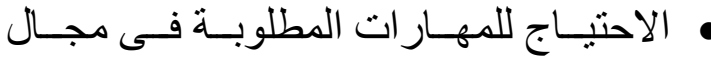

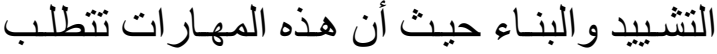

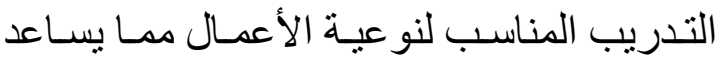
على رفع تكاليف الأجور.

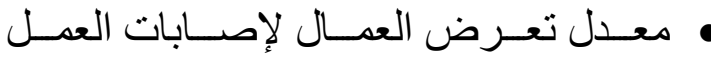

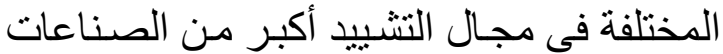

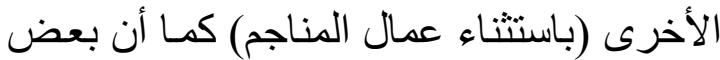

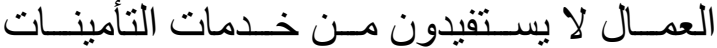
وخاصة من بعملون لدى صغار المقاولين.

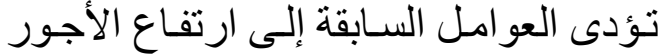

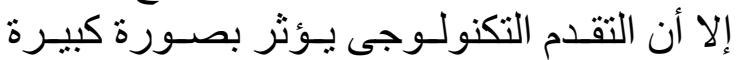

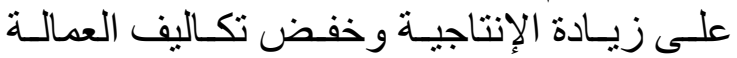
وذلك عن طريـق اسـتخدام المعدات الميكانيكيـة و الطرق الآلية و الطاقة، فالعمالة اليدويـة التقليديـة التية

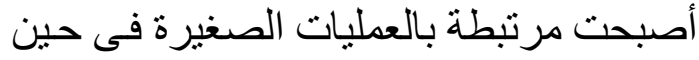

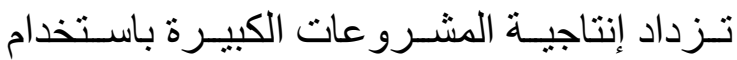
الطرق الآلية و التى تسـاعد على خفض تكاليف

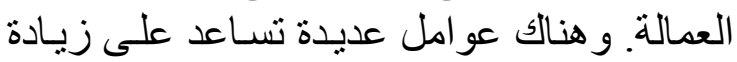
إنتاجية الأعمال وخفض تكاليف العمالة منها:

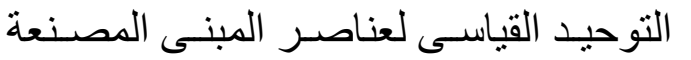

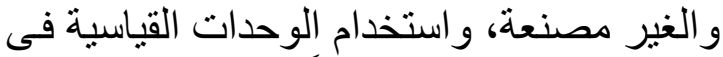

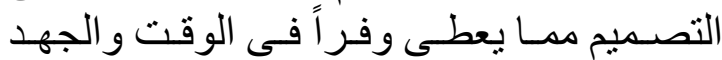

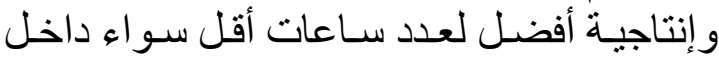

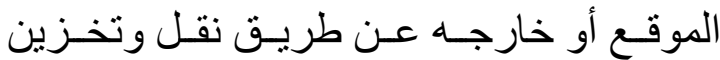

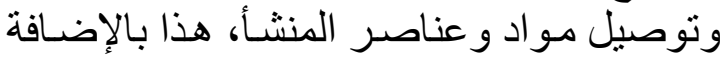
إلى كفاءة ألأعمال ودقة ادونة تنفيذها. 
BUILDING", BRITISH COUNCIL, P82.

[10]- Hassan Fathi, " ARCHITECTURE FOR THE POOR" The American University in Cairo Press, $2^{\text {nd }}$. Printing, 1989.

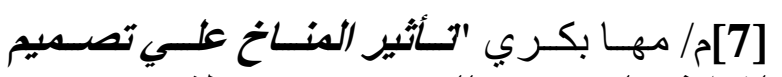

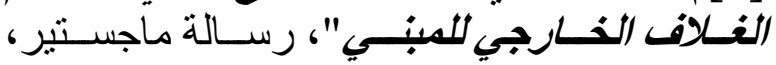

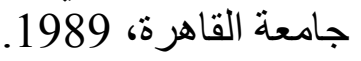

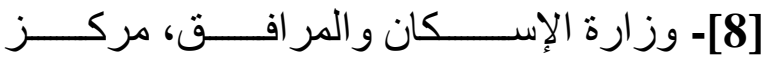

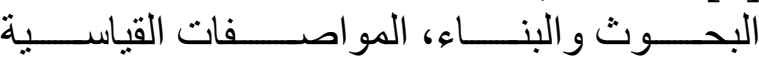

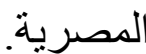

[9]- Ferry D. J. \& Prandon. S. "COST PLANNING OF 